\title{
BMJ Open Evaluation of the quality of contracted family doctor services based on patient perceptions and expectations: a follow- up analysis from the elderly with chronic diseases in rural Jiangsu, China
}

\author{
Shengxuan Jin (D) , ${ }^{1,2}$ Zhonghua Wang, ${ }^{1,2}$ Lanlan Tian, ${ }^{1}$ Zhenyu Sun, ${ }^{1}$ \\ Zhenping Lin,, ${ }^{1,2}$ Dongfu Qian ${ }^{1,2,3}$
}

To cite: Jin S, Wang Z, Tian $\mathrm{L}$, et al. Evaluation of the quality of contracted family doctor services based on patient perceptions and expectations: a follow-up analysis from the elderly with chronic diseases in rural Jiangsu, China. BMJ Open 2021;11:e053452. doi:10.1136/ bmjopen-2021-053452

- Prepublication history for this paper is available online. To view these files, please visit the journal online (http://dx.doi. org/10.1136/bmjopen-2021 053452).

Received 17 May 2021

Accepted 22 November 2021

Check for updates

(c) Author(s) (or their employer(s)) 2021. Re-use permitted under CC BY-NC. No commercial re-use. See rights and permissions. Published by BMJ.

${ }^{1}$ School of Health Policy and Management, Nanjing Medical University, Nanjing, China ${ }^{2}$ Institute of Healthy Jiangsu Development, Nanjing Medical University, Nanjing, China

${ }^{3}$ Center for Global Health, Nanjing Medical University, Nanjing, China

Correspondence to Dr Dongfu Qian; dqian@njmu.edu.cn

\section{ABSTRACT}

Introduction The policy focus of contracted family doctor services (CFDS) has been shifting to improve quality and efficiency in China. The study's objective was to establish a quality evaluation scale for CFDS based on the perceived service quality model and to assess the service quality from the perspective of patient perceptions and expectations.

Methods Data were obtained from a 2-year follow-up survey of CFDS in Jiangsu, China. A total of 1264 elderly people with chronic diseases were tracked. The self-developed scale was designed based on the perceived service quality model. The product scale method was used to assign weighted values, the Wilcoxon signed-rank test was used to compare the differences over the 2 years, and pooled cross-sectional regression was conducted to evaluate the associated factors with the gap scores of service quality.

Results There were significant differences between perceptions and expectations in each dimension in the 2 years $(p<0.05)$, and the service quality gaps existed. Over the 2 years, Accessibility and Horizontal continuity were the first-ranked and second-ranked in expectations; the top three scores in perception were Horizontal continuity, Comprehensive service and Accessibility dimensions. The service quality gap in 2020 was smaller than that in $2019(p<0.05)$. There were differences in the perception scores in the Vertical continuity, Technical and Economic dimensions and in the expectation scores in the Horizontal continuity, Vertical continuity and Technical dimensions between the 2 years $(p<0.05)$. The factors that were significantly associated with each dimension score included the Jiangsu region, gender, age and education levels $(\mathrm{p}<0.05)$.

Conclusion The quality evaluation scale of CFDS has good reliability and validity. Policy efforts should be focused on accelerating the development of medical alliances, optimising medical insurance policies and improving the capacity of family doctor services to meet the needs of the elderly with chronic diseases.

\section{INTRODUCTION}

Over the past 30 years, family doctors have provided personal healthcare in the context of the family and community, influenced

\section{Strengths and limitations of this study}

- This study is one of the first to evaluate the quality of contracted family doctor services from the perspective of patients' expectations and perceptions and compare the change through a 2-year-follow-up study of the elderly.

- The quality evaluation scale showed good reliability and validity and is of great significance to the evaluation of family doctor services in China and developing countries.

- The quality of the services has improved with time, but there were still negative gaps between perceptions and expectations, especially attention should be focused on the Economic, Vertical continuity and Technical dimensions of the delivery system of family doctor services.

- The research was based entirely on self-reports, which require people to recall their situation and are, therefore, subject to problems of biased memory.

- Some unmeasured confounders could have led to a potential residual confounding of the data.

medical education and changed the nature of healthcare in many countries around the world. ${ }^{1}$ To change the healthcare service model in primary health institutions and provide proactive, continuous and comprehensive health accountability management with residents, ${ }^{2}$ Chinese government agencies jointly released the 'Guiding Opinions on Promoting Contracted Family Doctors Services' ${ }^{3}$ in 2016 , which proposed a model of contracted family doctor services (CFDS) and established the family doctor as the first person responsible for the contracted service. In China, family doctors, including general practitioners registered with primary health institutions, qualified doctors at township clinics and village doctors, deliver basic medical care, public health and health 
management services in the form of teamwork. CFDS is based on the principle of full notification, voluntary contract signing and standardised service. ${ }^{2}$

In recent years, China has been exploring the implementation of CFDS systematically in several cities, such as Beijing, Shenzhen, Zhejiang and has achieved remarkable results. ${ }^{45}$ However, there are problems associated with the delivery processes, such as pursuing a high contract rate that neglects the quality of the services, low awareness, acknowledgement and satisfaction with contract services. ${ }^{6-8}$ Given that the policy in 2018 proposed that the focus of CFDS work should shift to improve quality and efficiency, ${ }^{9}$ how should we scientifically evaluate the current quality of contracted service? Also, how do we effectively improve CFDS quality based on existing resources? These questions must be addressed to further promote CFDS and contribute to the healthy, effective and sustainable development of rural health services.

According to relevant research, the perceived service quality model is considered a typical model of current service quality evaluation, and regarding service quality, it is a kind of customer perception that is affected by the customer's expectation and the actual perception of service. The core of the model is to evaluate the quality of service from the perspective of users. When the actual experience meets the customer expectation, the customer perceived quality is good; if the perception does not meet the expectation, the customer-perceived quality will be poor even if the actual quality meets the objective standard. ${ }^{10}$ Later, the Servqual (service quality) scale as a multiple-item scale was developed after numerous modifications as an instrument to measure service quality ${ }^{11}$ that corresponds to the dimensions of the consumer perceptions of service quality model and is widely used in the medical field. In terms of the quality evaluation tool for CFDS, relevant studies ${ }^{12}$ summarised methods including the WHO Primary Care Assessment Tool (PCAT), the ADHD Questionnaire for Primary Care Providers and the General Practice Assessment Questionnaire. Among them, the PCAT is usually considered the most appropriate tool to evaluate primary healthcare. The CFDS is a part of primary healthcare and has unique characteristics combined with the actual situation of rural China. However, in most of the existing studies in China, service quality of family contracted service was reflected in crosssectional studies, measuring service satisfaction and residents' trust or willingness or the influencing factors with family physicians, ${ }^{13-15}$ while there are a few studies using a scale to evaluate quantitatively consumer perceptions of service quality about CFDS in China in the available literature.

Against the background of patient-centred care and providing the best possible medical care for patients, the pressure on healthcare management is increasing. Therefore, understanding patients' service quality perceptions and expectations, which are a significant driving force that explains the relationship between health service quality and utilisation, ${ }^{16}$ is one of the most important steps in implementing reform in the health sector. In particular, as an important measure of graded diagnosis and treatment, it is important for family doctors to understand patients' experiences. Even so, little research has been conducted to examine patients' perceptions and expectations in the quality of CFDS, but the perceived service quality model provides a feasible framework for analysing the service quality of family doctors from the perspective of patients.

Compared with urban areas, rural areas have fewer health resources and a larger proportion of elderly people ${ }^{17}$ which is one of the key groups contracted by family doctors. This phenomenon reflects the contradiction between health service demand and need and healthcare supply more broadly. Therefore, the purpose of this study was to evaluate the service quality of CFDS from the perceptions and expectations of elderly patients with chronic diseases in rural areas based on the perceived service quality model. First, we developed a set of scales to evaluate the quality of CFDS, which provides an applicable and popularised tool for the measurement of CFDS in China. Afterwards, we conducted an empirical analysis with a 2-year follow-up evaluation of the same population to provide evidence for health policymakers to further optimise CFDS for the elderly in China.

\section{METHOD}

\section{Study sample and data collection}

This study used pooled cross-sectional data from a 2-year follow-up survey of CFDS in 1 July 2019 and 17 July 17 2020, in the province of Jiangsu, China. The typical sampling method and stratified-cluster sampling method were conducted to select the participants. First, three typical counties (districts) of South, Middle and north Jiangsu Province were selected by the typical sampling method. The primary features were the contract service mode (including contract service package and service fee payment method), the level of social and economic development and local acceptance and cooperation conditions. The sample counties (districts) were Wujin District of Changzhou City, Rudong County of Nantong City and Dafeng District of Yancheng City. Second, the townships were selected by the stratified cluster sampling method, and all the townships in the sample counties (districts) were divided into three levels (good, medium and poor) based on the GDP ranking. Then, one township was selected randomly from each level. Third, three villages were selected randomly from each sampled township.

The eligibility criteria of participants were (1) age ( $\geq 60$ years), (2) being contracted to a family doctor in the past year, (3) having diabetes or high blood pressure, (4) having the capacity for independent judgement and the willingness to participate in a survey and (5) having lived in the district for over 6 months. Other residents who were suffering from serious diseases (eg, cancer and AIDS) were excluded. A total of 1690 valid questionnaires were collected in the first wave (2019). The second 
tracking survey was conducted 1 year later (2020), when 1782 questionnaires were collected. After matching the subjects by region, name and gender for 2 years, a total of 1264 people were tracked to the survey population, and the effective sample size was 2528. In regression analysis, it has been reported that the calculation method of sample size is more than 10 times the number of independent variables. The effective sample size for continuous outcomes in linear regression analysis is determined by the total number of observed objects. ${ }^{18}$

\section{Quality evaluation scale and questionnaire design}

Based on the perceived service quality model and using the PCAT questionnaire for reference, our quality evaluation scale and questionnaire were formed after making appropriate changes combined with the service requirements and agreement content of CFDS in China. ${ }^{19}$ This questionnaire was divided into two parts, involving general characteristics (ie, age, sex, marital status, education, general income and outcome, chronic diseases) and service quality evaluation. It included a 24-item scale each for expectations and perceptions in six dimensionsAccessibility (items 1-4), Horizontal continuity (items 5-8), Vertical continuity (items 9-13), Comprehensive service (items 14-18), Technical (items 19-21) and Economic (items 22-24). The dimensions are described below:

1. Accessibility: get timely treatment and help from family doctors; the distance and time spent should be reasonable.

2. Horizontal continuity: explanations of diagnosis and treatment should be readily comprehensible; the family doctors should be familiar with patients' health problems, medication use and family status.

3. Vertical continuity: the doctors should recommend, make contacts, book appointments and fill in the reasons for referrals to the superior hospital for diagnosis and treatment. In addition, they should provide follow-up treatment and visits for downstream referral patients.
4. Comprehensive service: the doctors should provide different types of health services, such as health examination and assessment, blood pressure monitoring, blood glucose monitoring and follow-up, health behaviour guidance and mental health guidance.

5. Technical: they should have a good technical level of diagnosis and treatment and should provide medication guidance and control disease well.

6. Economic: drug cost, consultation fees and examination fees should be acceptable, and it should be more cost-effective to see a doctor after signing a contract.

In the question, the perception was introduced to respondents as: "the actual experience of the quality of CFDS, if you think the service provided is satisfactory, please give it high marks; lower marks means dissatisfaction'. The expectation was introduced as: 'What level of service quality do you expect family doctors to sign contracts with, rather than the experienced service quality'. The perception and expectation variables were measured on a 5-point Likert scale ranging from $1=$ 'strongly disagree' to $5=$ 'strongly agree' according to common methods. Higher scores on each item showed that patients had more positive expectations and perceptions regarding the quality of services. An additional option of 'do not know/not sure' was added in case of a lack of knowledge regarding a certain item, and this option was assigned to the middle of the adjacent points.

Cronbach's alpha values were computed to determine the level of reliability between perceptions and expectations. In the 2019 questionnaire, Cronbach's alpha of the whole scale in expectations and perceptions was 0.909 and 0.892, respectively. In 2020, Cronbach's alpha was 0.921 and 0.947 in expectations and perceptions, respectively. All six dimensions had alpha values exceeding the 0.7 threshold value. The results showed that the expectations and perceptions of the Kaiser-Meyer-Olkin values in 2019 were 0.893 and 0.874 , respectively; in 2020, they were 0.921 and 0.947 , respectively. The $p$ values reached a

Table 1 Analysis of the reliability of the service quality scales

\begin{tabular}{|c|c|c|c|c|c|c|}
\hline \multirow[b]{2}{*}{ Dimensions } & \multicolumn{2}{|l|}{2019} & \multicolumn{2}{|l|}{2020} & \multicolumn{2}{|l|}{ Total } \\
\hline & Perceptions & Expectations & Perceptions & Expectations & Perceptions & Expectations \\
\hline Accessibility & 0.808 & 0.803 & 0.829 & 0.907 & 0.819 & 0.876 \\
\hline Vertical continuity & 0.913 & 0.948 & 0.843 & 0.936 & 0.905 & 0.944 \\
\hline Comprehensive service & 0.863 & 0.822 & 0.864 & 0.907 & 0.864 & 0.875 \\
\hline Economic & 0.741 & 0.809 & 0.818 & 0.890 & 0.782 & 0.866 \\
\hline Total & 0.909 & 0.892 & 0.926 & 0.953 & 0.918 & 0.930 \\
\hline $\mathrm{KMO}$ & 0.893 & 0.874 & 0.921 & 0.947 & 0.915 & 0.932 \\
\hline$\chi^{2}$ & 18077.749 & 19953.155 & 16438.741 & 28767.693 & 33870.603 & 48282.093 \\
\hline $\mathrm{P}$ & $<0.001$ & $<0.001$ & $<0.001$ & $<0.001$ & $<0.001$ & $<0.001$ \\
\hline
\end{tabular}


significant level $(<0.001)$, indicating good questionnaire structure validity. The details are shown in table 1.

\section{Data analysis}

In this paper, the quality of service is reflected by the difference between perceptions $(\mathrm{P})$ and expectations of elderly patients with chronic diseases $(\mathrm{E})(\mathrm{Q}=\mathrm{P} \mathrm{E})$. When $\mathrm{Q}$ is negative, there is a gap in service quality, and a large absolute value of $Q$ indicates a large gap in service quality. ${ }^{20}$ In contrast, when $Q$ is positive, patients' expectations are greater than their perceptions. The service expectation of contracted residents was regarded as the importance of this dimension, and the product scale method was used to assign weighted values to each dimension. ${ }^{21}$ Equation (1) was employed to estimate the service quality gap score of each dimension.

$$
Q i=\frac{1}{k} \sum_{\mathrm{m}=1}^{k}(\overline{P m}-\overline{E m})
$$

where $Q i$ refers to the quality gap score of dimension $i, k$ is the number of indicators in each dimension, $\overline{P m}$ is the average perceived value of index $m$ of this dimension, and $\overline{E m}$ is the average expected value of index $m$ of this dimension.

Equation (2) employs the total service quality gap value:

$$
T Q=\sum_{i=1}^{n} W i Q i
$$

where $W i$ represents the weight of the $i$ dimension calculated by the product scale method and $n$ represents the number of all dimensions included in the scale.

\section{Statistical analysis}

A descriptive analysis was conducted to describe the sample characteristics and to compute the means and SD for continuous variables, frequencies and percentages for categorical variables. Confirmatory analyses were carried out to examine the measurements of the study and their reliability and validity. The product scale method was used to assign weighted values. As the samples did not meet the normal distribution, the Wilcoxon signed rank test was used to compare the gap between perceptions and expectations, and the difference between patients' perceptions, expectations and gap scores in family doctor services at the 2-year mark. Pooled cross-section regression was conducted to evaluate the associated factors with the gap scores of the quality of CFDS. When $p<0.05$, the results were statistically significant. The collected data were entered using Epidata, and all analyses were performed using the statistical package STATA V.14 and SPSS V.23. The variables are described in table 2.

\section{Patient and public involvement statement}

Patients and the public were not involved in the design and conduct of this research.

\section{RESULTS \\ Socioeconomic characteristics of the elderly with chronic diseases}

Table 3 presents an overview of the sociodemographic data of the participants with the number $(\mathrm{N})$ and the

Table 2 Descriptions of dependent and independent variables

\section{Categories}

Dependent variables

Score of each dimension

Total score

Independent variables

Year

Region of Jiangsu

Gender

Age

Marital status

Education levels
Family size

Annual household outcome (yuan)

Chronic diseases

Suffering from two or more chronic diseases

Buy medications from family doctor

Get medication guidance from family doctor
Accessibility, horizontal continuity, vertical continuity, Comprehensive service, technical, economic (continuous variable) Total score (continuous variable)

$=1,2019 ;=2,2020$

$=1$, south; $=2$, northern; $=3$, central

$=1$, male; $=2$, female

$=1,[60,75) ;=2, \geq 75$

$=1$, married; $=2$, else

$=1$, illiteracy; $=2$, primary;

$=3$, junior high school; $=4$, high school and above

$=1$, single; $=2$, two persons; $=3$, three persons and above

$=1,<5000 ;=2$, [5000, 10 000); =3, [10 000, 15 000)

$=4,[15000,20000) ;=5, \geq 20000$

$=1$, hypertension; $=2$, diabetes

$=1$, yes; $=2$, no

$=1$, yes; $=2$, no

$=1$, yes; $=2$, no 
Table 3 Sample characteristics of participants

\begin{tabular}{ll} 
Characteristics & Participants, N (\%) \\
\hline Total & $\mathrm{n}=1264$
\end{tabular}

Region

\begin{tabular}{|c|c|}
\hline Southern Jiangsu & $394(31.2)$ \\
\hline Northern Jiangsu & $439(34.7)$ \\
\hline Central Jiangsu & $431(34.1)$ \\
\hline \multicolumn{2}{|l|}{ Gender } \\
\hline Male & $582(46.0)$ \\
\hline Female & $685(54.0)$ \\
\hline \multicolumn{2}{|l|}{ Age (year) } \\
\hline$[60,75)$ & $914(72.3)$ \\
\hline$\geq 75$ & $350(27.7)$ \\
\hline \multicolumn{2}{|l|}{ Marital status } \\
\hline Married & $1047(82.8)$ \\
\hline Else & $217(17.2)$ \\
\hline \multicolumn{2}{|l|}{ Education levels } \\
\hline Illiteracy & $322(25.5)$ \\
\hline Primary & $518(41.0)$ \\
\hline Junior high school & $330(26.1)$ \\
\hline High school and above & $94(7.4)$ \\
\hline \multicolumn{2}{|l|}{ Resident population of family } \\
\hline Single & $141(11.2)$ \\
\hline Two persons & $698(55.2)$ \\
\hline Three persons and above & $425(33.6)$ \\
\hline \multicolumn{2}{|c|}{ Annual household outcome (yuan) } \\
\hline$<5000$ & $172(13.7)$ \\
\hline$[5000,10000)$ & $296(23.2)$ \\
\hline$[10000,15000)$ & $240(19.1)$ \\
\hline$[15000,20000)$ & $131(10.4)$ \\
\hline$\geq 20000$ & 418 (33.3) \\
\hline
\end{tabular}

Suffering from two or more chronic diseases

$\begin{array}{lc}\text { Yes } & 1142(90.3) \\ \text { No } & 122(9.7) \\ \text { Chronic diseases } & \\ \text { Hypertension } & 290(22.9) \\ \text { Diabetes } & 974(77.1)\end{array}$

Buy medications from family doctor

\begin{tabular}{lc} 
Yes & $1074(85.4)$ \\
\hline No & $184(14.6)$ \\
Get medication guidance from family doctor \\
\hline Yes & $1144(90.9)$ \\
\hline No & $114(9.1)$ \\
Prefer to see family doctor & \\
Certainly & $612(49.5)$ \\
\hline Often & $511(41.3)$ \\
\hline Not really & $114(9.2)$ \\
\hline
\end{tabular}

corresponding percentages. The research object was a follow-up survey of the same group of people for 2 years, and the population characteristics were basically unchanged. Therefore, this part showed the data of the population characteristics in 2019. In total, 1264 participants were tracked and included in our analysis, of whom $394(31.2 \%)$ were from South Jiangsu, and 439 (34.7\%) were from Northern Jiangsu. Most of the respondents were women $(54.0 \%)$ and married $(82.8 \%)$, had an education level of at least primary school $(74.5 \%)$, had two people in the family (55.2\%) and earned 20000 yuan or more in annual household income (33.3\%). The largest proportion of participants $(72.3 \%)$ was in the 60-75 year age group. In terms of chronic disease, most of the participants had two or more disease $(90.3 \%)$, of which diabetes was the most common $(77.1 \%)$. Additionally, $85.4 \%$ of respondents bought medications from their family doctor, $90.9 \%$ of them received medication guidance from their family doctor and patients were also more likely to visit their family doctor.

\section{The elderly's expectations and perceptions of the quality of CFDS}

Weights were given according to the product scale method for the importance of each dimension. For the six dimensions of Accessibility, Horizontal continuity, Vertical continuity, Comprehensive service, Technical and Economic, the ranks of patients' expectations in 2019 were 2, 1, 6, 5,4 and 3, respectively, and 1, 2, 6, 3, 5 and 4 in 2020, respectively. Therefore, the weights of each dimension in 2019 were $0.230,0.312,0.069,0.093,0.126$ and 0.170 . The weights were $0.312,0.230,0.069,0.170,0.093$ and 0.126 , in 2020 .

Table 4 shows patients' perceptions, expectations and service quality gap scores between the 2 years. The results of 2019 showed that patients had the highest perceptions for the Horizontal continuity dimension (4.595), followed by Accessibility (4.511), and the lowest score for Vertical continuity (3.491). Regarding the expectations of the quality of the services, Horizontal continuity (4.876) was again highest, followed by Accessibility (4.862), and Vertical continuity was the lowest (4.316). Regarding the gap of service quality, the greatest was for Vertical continuity $(-0.822)$, followed by Economic (-0.662) and Technical (-0.556). In 2020, the highest perception was Horizontal continuity (4.609), the highest expectation was Accessibility (4.803) and the greatest gap was for Economic (-0.394), followed by Vertical continuity $(-0.392)$. Significant differences in patients' expectations and perceptions existed in 2019 and $2020(\mathrm{p}<0.05)$.

At the same time, the result of the Wilcoxon signed rank test showed differences in the 2 years of perception scores in the Vertical continuity, Technical and Economic dimensions $(p<0.01)$. Expectation scores were different in the Horizontal continuity, Vertical continuity and Technical dimensions $(p<0.05)$. Moreover, the scores of service quality gap presented statistically significant differences in each dimension in the 2 years $(\mathrm{p}<0.01)$. The radar 
chart shown in figures 1-3 provides more detail about the scores of patient's perceptions, expectation and quality gap between patients interviewed in 2019 and 2020. In terms of perceptions, the improvement in the Vertical continuity $(0.660,18.91 \%)$, Economic $(0.191,4.57 \%)$ and Technical $(0.105,2.46 \%)$ dimensions was statistically significant through the comparison of the 2 years' scores. As for expectations, there was statistical significance. Except for Vertical continuity $(0.257,5.95 \%)$, all other dimensions decreased, including Technical $(-0.072$, $-1.49 \%)$ and Horizontal continuity $(-0.083,-1.70 \%)$. Respondents who were interviewed in 2019 had higher services gap scores in all six domains than those interviewed in $2020(\mathrm{p}<0.01)$. The dimensions ranked from largest to smallest were as follows: Vertical continuity $(0.430,52.31 \%)$, Economic (0.268. 40.48\%), Horizontal continuity $(0.096,34.29 \%)$, Technical $(0.177,31.83 \%)$, Comprehensive service $(0.097,29.94 \%)$ and Accessibility $(0.082,23.43 \%)$. The overall quality score was increased by 0.161 , to $36.84 \%$.

Regression results of the quality gap of family doctor service

Pooled cross-sectional regression was performed to examine the quality of contract services by controlling for other influencing factors. The results in table 5 show that the patients who received contract services in 2020 reported higher points on six dimensions and total domain scores than those who received services in 2019. Besides, factors significantly associated with each dimension scores included people in the region of Jiangsu, gender, age and education levels $(\mathrm{p}<0.05)$. In the dimension of Comprehensive service, the service in northern Jiangsu demonstrated better, but in other dimensions, the service evaluation scores in southern Jiangsu were all higher than other regions. Furthermore, women aged 75 years and older, and had higher education, received lower quality scores in each dimension $(\mathrm{p}<0.05)$. Among other factors, the elderly with more than two chronic diseases in the Comprehensive and Vertical continuity dimension, who bought medication and received guidance from family doctors in the Technical dimension, and bought medicine from family doctors in the Economic dimension, obtained higher scores $(\mathrm{p}<0.05)$.

\section{DISCUSSION}

As the key clients for CFDS, it is of great significance to evaluate service quality from the perspective of the perceptions and expectations of the elderly population with chronic disease, so as to improve family doctors' abilities and optimise the services. In this study, we developed a scale to evaluate the quality of CFDS and then analysed the gap between perceptions and expectations based on the perceived service quality model. Specifically, we compared the change in the expectations and perceptions of the elderly over 2 years through a follow-up study and evaluated the associated factors with the service quality, thereby providing an accurate reference for the 


\section{Perceptions}

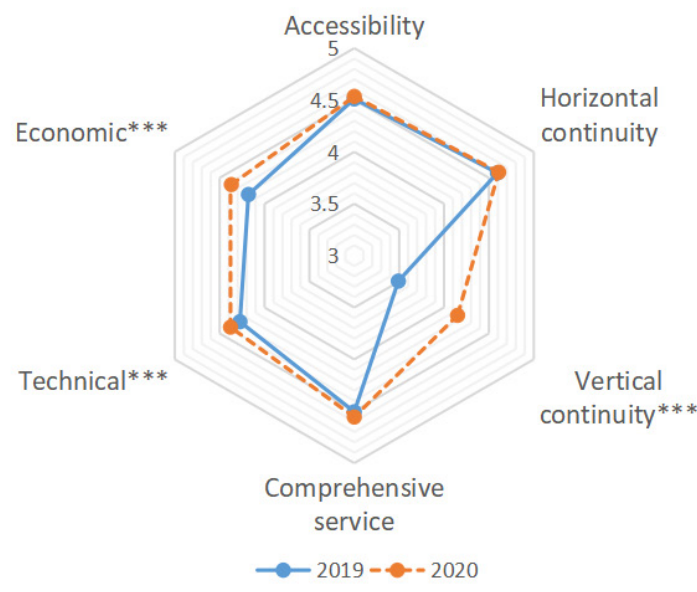

Figure 1 Scores of patient's perceptions between patients interviewed in 2019 and 2020.

improvement of service quality in each dimension. This study is one of the first to evaluate the quality of CFDS from the perspective of patients' expectations and perceptions.

\section{Expectation of service quality among elderly with chronic diseases}

Patient expectations refer to the health services expected by the elderly with chronic diseases before receiving medical services and are influenced by experience, public opinion, the image of medical institutions and oral communication from relatives and friends. ${ }^{22}$ The dimensions of Accessibility and Horizontal continuity were the first-ranked and second-ranked dimensions in the 2 years. This may reflect that patients pay more attention to the content of contracted services in these two dimensions. For the Accessibility dimension, the elderly populations with chronic disease in rural areas expect to get nearby and continuous services owing to their poor health condition and their medical service needs, which mainly focus on medicine and chronic disease monitoring. As for the Horizontal continuity dimension, relevant studies showed that when family doctors have a better understanding of patients' diseases, risk factors and family background, the cost of establishing effective connections between the patient and the family doctor can be reduced. ${ }^{23}$ Therefore, strategies for improving Accessibility and Horizontal continuity of contracted family doctors' services

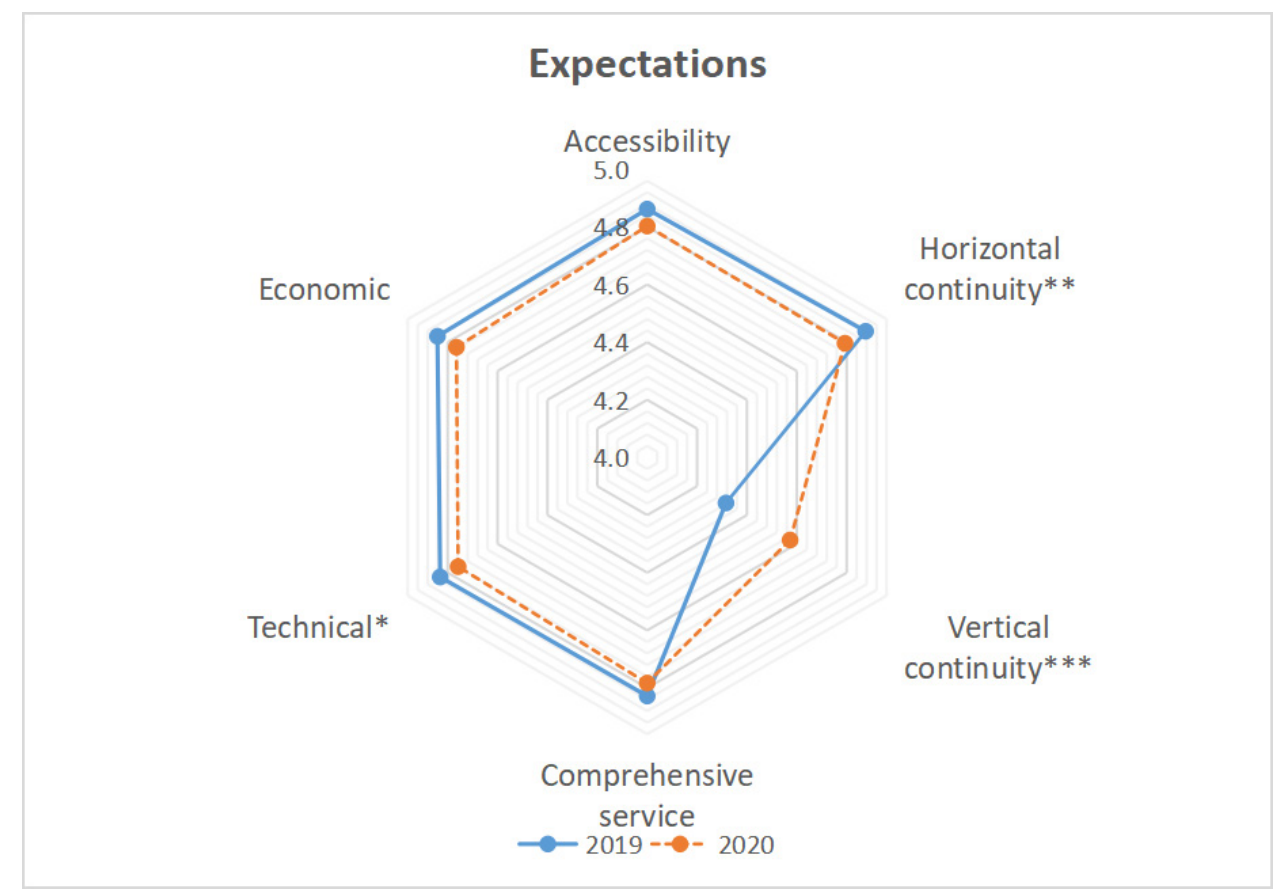

Figure 2 Scores of patient's expectations between patients interviewed in 2019 and 2020. 


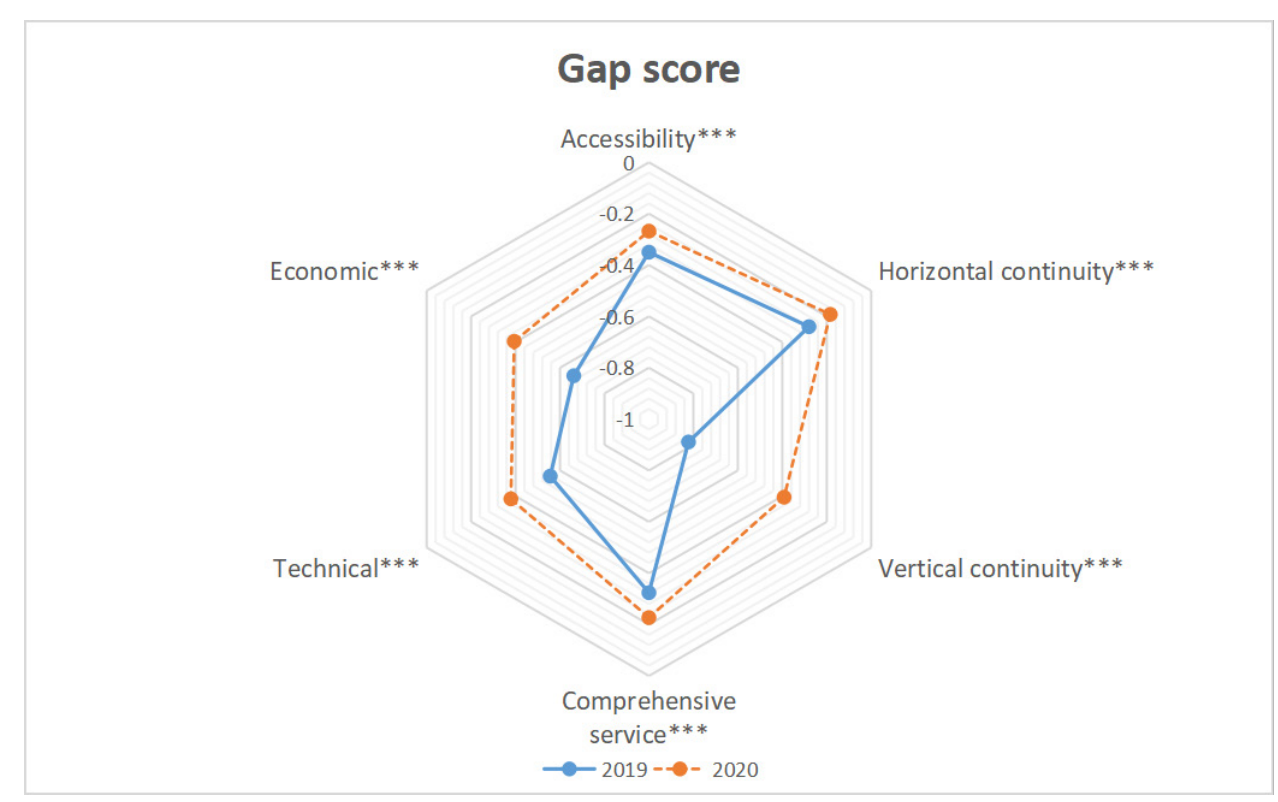

Figure 3 Scores of patient's quality gap between patients interviewed in 2019 and 2020.

should be developed for the elderly with chronic diseases. First, primary hospitals should ensure the supply of essential drugs, provide health education and physical examination for chronic diseases in township and village clinics. Second, family doctors should strengthen communications with patients and establish a close and harmonious doctor-patient relationship to promote the continuity of services. In addition, previous studies pointed out that mobile phone-based monitoring and feedback system was effective in chronic disease control as well as in primary care clinics. ${ }^{24}{ }^{25}$ Therefore, mobile monitoring equipment could be used to provide real-time and dynamic health monitoring for the elderly with chronic diseases in rural areas.

The scores for Vertical continuity in 2020 were significantly higher than those in 2019 , but the figures were lower in Horizontal continuity and Technical dimensions in 2020. The decrease in the expectation score may be due to the fact that patients' needs in these two dimensions are met, and the expected key content is changed under the condition of the development of family doctor services. The expected score of Vertical continuity also improved, revealing that the elderly with chronic diseases pay more attention to up-down referral services, which puts forward future directions for the improvement of CFDS.

\section{Perceptive service quality among elderly with chronic diseases}

Patient perceptions refer to actual feelings about the quality of service provided by the hospital after receiving medical service ${ }^{22}$ which in turn reflects the patient's feedback on the effectiveness of the service. The Horizontal continuity, Comprehensive service and Accessibility dimensions scored the highest over the 2 years, which was consistent with the results of Kuang et $a l^{26}$ whose report showed that contracted residents had high scores in the dimensions of first-contact access, continuity and comprehensiveness. The CFDS is provided by the family doctor of the village, and their services are closely related to the needs of older people in rural areas. So it plays a good role.

The Vertical continuity dimension was the lowest in both 2019 and 2020, reflecting the relatively low quality of referral service in CFDS. On the one hand, it may be due to the inadequate health information system and communication in rural areas, which lead to the imperfect up-and-down referral system and impede the referral process. ${ }^{27}$ On the other hand, it may be that family doctors may have unclear cognition of their responsibilities and low initiative in the process of promoting two-way referral service, which needs further systematic management and supervision. ${ }^{28}$ Elderly people with chronic diseases also have a higher demand for the referral of CFDS. Therefore, it is necessary to learn from the experience of the USA, which medical institutions have a clarified functional division, laying a foundation for establishing the graded diagnosis and treatment system. ${ }^{29}$ In order to improve the quality of Vertical continuity of CFDS, first, policies should accelerate the construction of closer county-level medical alliances, so as to make the referrals between secondary hospitals and primary hospitals effectively. Second, informatization construction should be strengthened to realise the sharing of medical information. ${ }^{30}$ At the same time, an effective benefit distribution mechanism should be established to mobilise the enthusiasm of medical institutions at all levels.

\section{Patients' expected and perceived quality of service gap}

The results showed that in all six dimensions of service quality, the perceptions of respondents were lower than their expectations, indicating that the service quality of CFDS still needs to be improved, which is in line with previous surveys for healthcare. ${ }^{16}{ }^{22}$ In 2019 , the gap in the Vertical continuity dimension was the largest, while in 2020, the largest gap was in the Economic dimension. 


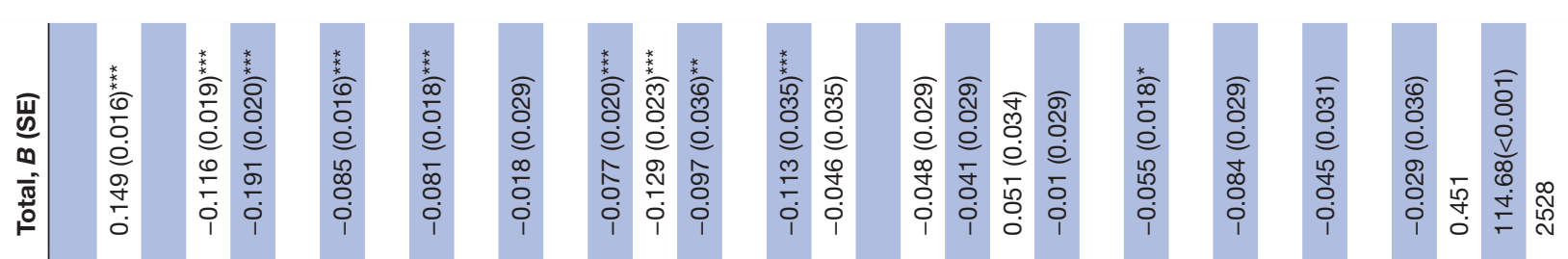

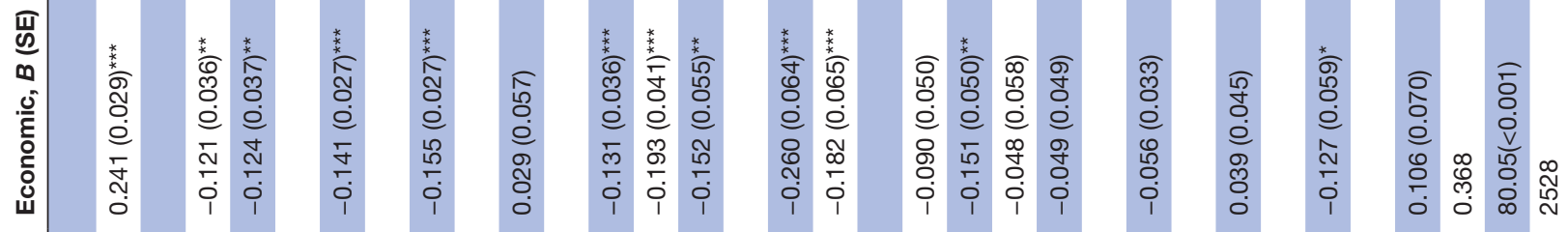

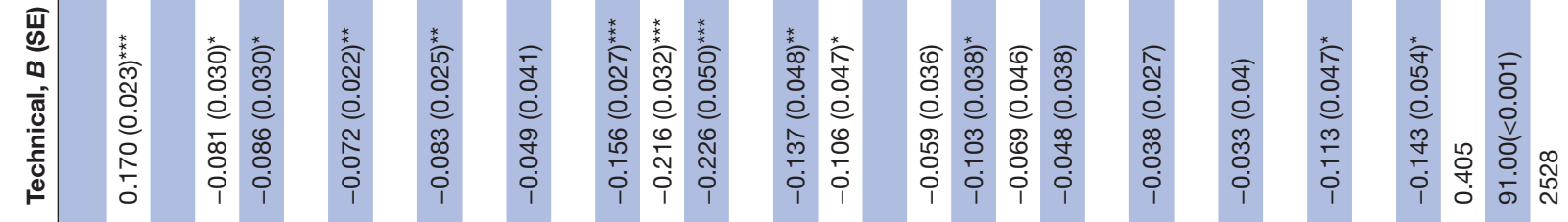

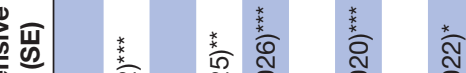

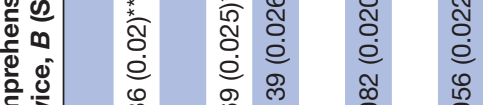

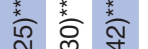

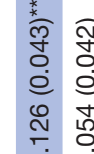

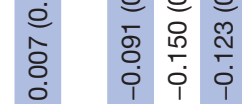
$\begin{array}{lll}0 & 0 & 0 \\ 0 & 0 & 0 \\ 0 & 0 & 0\end{array}$ i

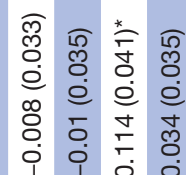

\section{离}

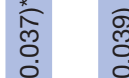

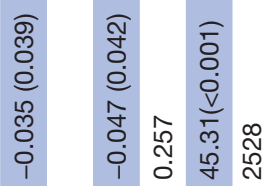

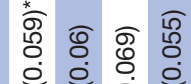

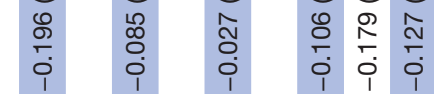

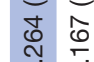

กิ

8
8
0
0

담

c)

i

$\cdot \frac{0}{9}$

है

茯

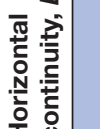

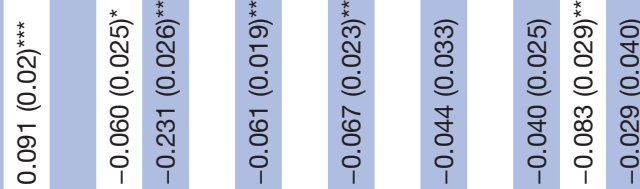

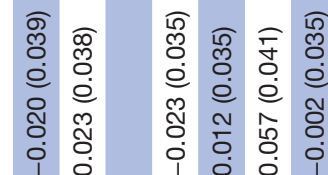

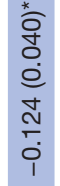

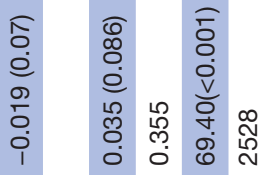

㟧

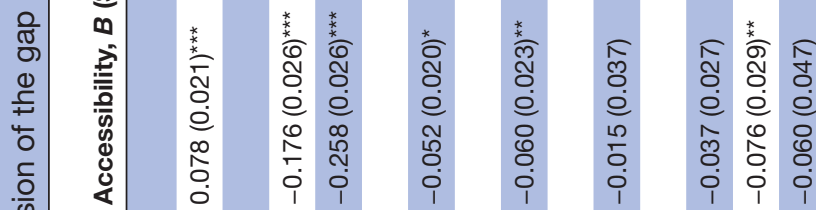

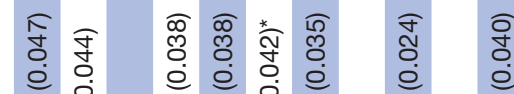

סू

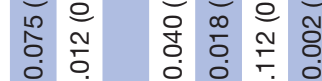

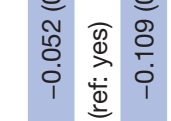

움 क

0
0
0
0
0
0
0
0
$\overline{0}$
0
0
0
0
0
0
0
0
$\frac{0}{8}$
0

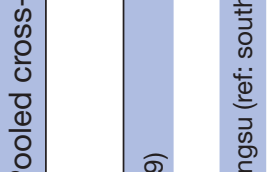

胥

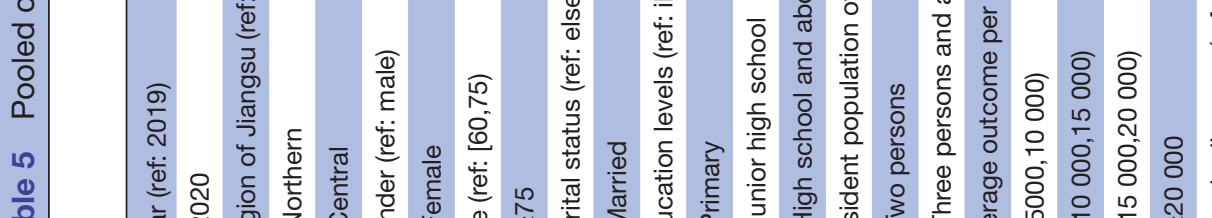
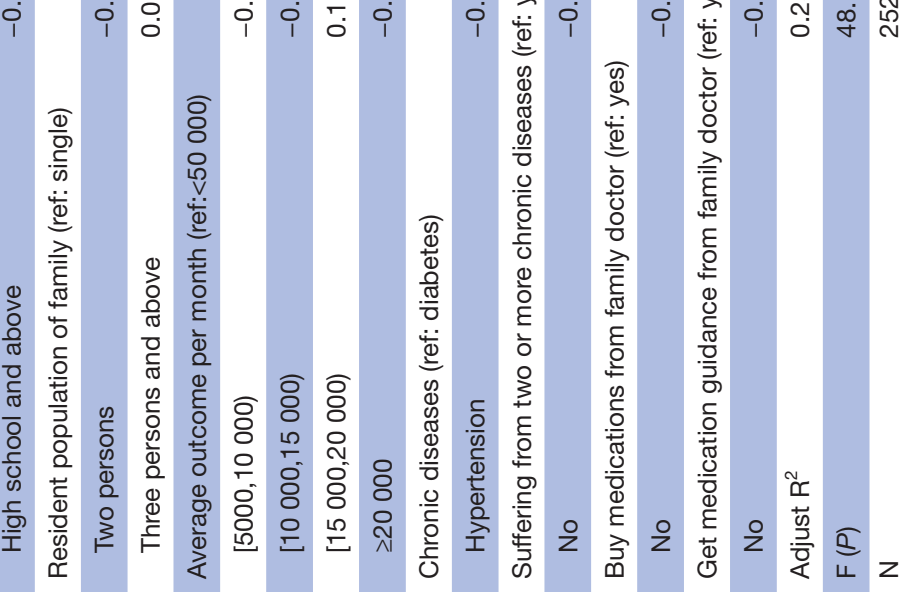

0
0

을

ก

N

एृ

$\stackrel{0}{\mathbb{D}}$

꿈 
The Technical, Accessibility, Comprehensive service and Horizontal continuity dimensions remained unchanged in the gap ranking over the 2 years. The result of the gap scores of the Vertical continuity dimension was consistent with the outcomes of the unsatisfied perceptions and the high score of the expectations, indicating the inadequacy of the current two-way referral services provided by family doctors. The reason for the large gap in the Economic dimension was the heavy economic burden of diseases among the elderly. Furthermore, as the participants were elderly people suffering from chronic diseases, their cost burden was relatively larger. ${ }^{31}$ Relevant studies ${ }^{32}$ indicated that universal medical insurance plays an important role in promoting the effective use of health services in rural areas. Therefore, the policy should focus on further improving the reimbursement level of medical insurance for patients with chronic diseases in primary hospitals.

The gap for the Technical dimension was ranked third, indicating a poor service quality, which may be attributed to the lack of medical personnel and medical equipment in rural areas. This is an important factor restricting the provision of family doctor services. ${ }^{33}{ }^{34}$ Besides, the main work of family doctors in China is to provide public health services or to prescribe drugs in medical services, which fails to reflect the diagnosis and treatment technology level to some extent. At the same time, the service capacity of family doctors still needs to be strengthened. For example, the facilities of primary hospitals should be strengthened to ensure the basic ability of examination and diagnoses. Moreover, family doctors should gradually enhance their medical and pharmaceutical knowledge and skills.

However, in terms of the service quality gap of each dimension, the gap in the second year narrowed, indicating that the service quality has improved in 2020. On the one hand, it is because of the national policy to improve the quality and efficiency of CFDS work, ${ }^{9}$ so that the management methods for CFDS assessment and supervision were released, promoting the improvement of quality. On the other hand, with the implementation of CFDS in China, the public has gradually accepted this service model, which is more conducive to the development of the project.

\section{Demographic characteristics and service quality gap}

Regional variables had significant negative impacts on the gap scores of each dimension, except for the Comprehensive dimension. The gap scores of southern Jiangsu were smaller than those of other regions, which reflected the difference in the allocation of health resources. The first reason may be the fact that, with the favourable economic development in southern Jiangsu Province, the training of family doctors and the construction of primary healthcare have been well developed. Furthermore, the advantages of the geographical location have attracted more medical talent. In the Comprehensive dimension, North Jiangsu scored higher, which may be related to the typical model of 'basic package +personality package', which is a contract service launched by Dafeng. As one of the five typical contract service modes of family doctors in China, the service content is relatively complete and the implementation is effective. Therefore, regional cooperation and exchanges should be strengthened to learn from experienced individuals about talent introduction and medical technology upgrading. In addition, the results showed that older people had a lower evaluation of service quality; this may owe to poor physical conditions and mobility difficulties of elderly patients, as they may expect diversified service types and may make pertinent demands. Therefore, it is suggested to further improve the precision of CFDS for older people with chronic diseases.

Moreover, there were some results with significant correlations. Specifically, in terms of the Vertical continuity and Comprehensive dimension, the elderly with more than two chronic diseases scored higher, revealing that the elderly was benefitting from the CFDS, because of their higher levels of demand for referral services and utilisation of health services. With regards to the Technical dimension, the elderly who bought medication and guidance from a family doctor gave a higher evaluation, indicating that elderly people were satisfied with the services technology. The reason may be that the ability of grassroots family doctors has improved with the implementation of a hierarchical diagnosis and treatment system. As for the Economic dimension, the elderly who bought medicine from family doctors had a higher score; this may be because of medical insurance policies in favour of CFDS and drugs.

There were several limitations to the study. First, the research was based entirely on self-reports, which require people to recall their situation and are, therefore, subjected to problems of biased memory. Second, Jiangsu is a relatively developed province, which indicates that the findings might not be extrapolated to the rural areas in central and western China. Third, as this study was a 2-year follow-up survey, the trend of quality change was not very significant, so further follow-up investigation and analysis are needed.

\section{Conclusion}

The quality of CFDS improved with time, but there were still negative gaps between the perceptions and expectations in the six dimensions, indicating that the expectations of patients have not been met, and the quality of family doctor services needs to be improved further. Attention should be focused on the Economic, Vertical continuity and Technical dimensions, which showed the largest quality gaps in 2020. Therefore, accelerating the development of medical alliances, optimising medical insurance policy and improving the capacity of the service should be effective measures to promote the development of CFDS and meet the needs of the elderly with chronic diseases. Other independent variables, such as the region of Jiangsu, age, chronic diseases and service utilisation, were found to significantly affect service quality score. Therefore, policy should focus on these factors, such as strengthen exchanges between regions to balance the coordination of health resources, to provide accurate contracted services to rural residents. Overall, the quality 
evaluation scale of the CFDS developed in this study had good reliability and validity and is of reference value to the evaluation of grassroots health service quality in other developing countries.

Acknowledgements The authors acknowledge the local Health Commission of Jiangsu province for their cooperation and thank all study participants in 'The Public Health Policy and Management Innovation Research Team' for their contributions to the overall work.

Contributors SJ led the analysis of the data and wrote the first draft of the manuscript; LT, ZS and ZL helped in data collection and cleaning; DQ and ZW contributed to the study design, interpretation of the data and helped in the writing of the final draft of the manuscript. All authors have read and approved the entire manuscript. DQ responsible for the overall content as the guarantor.

Funding This study was supported by grant 71874085 from the National Natural Science Foundation of China. The Public Health Policy and Management Innovation Research Team, Jiangsu, China, also provided support.

Competing interests None declared.

Patient and public involvement Patients and/or the public were not involved in the design, or conduct, or reporting, or dissemination plans of this research.

Patient consent for publication Consent obtained directly from patient(s).

Ethics approval This study involves human participants but this study was approved by the Ethics Commit of Nanjing Medical University Number (2017)449. Exempted this study participants gave informed consent to participate in the study before taking part.

Provenance and peer review Not commissioned; externally peer reviewed.

Data availability statement № data are available.

Open access This is an open access article distributed in accordance with the Creative Commons Attribution Non Commercial (CC BY-NC 4.0) license, which permits others to distribute, remix, adapt, build upon this work non-commercially, and license their derivative works on different terms, provided the original work is properly cited, appropriate credit is given, any changes made indicated, and the use is non-commercial. See: http://creativecommons.org/licenses/by-nc/4.0/.

\section{ORCID iD}

Shengxuan Jin http://orcid.org/0000-0001-7232-6040

\section{REFERENCES}

1 Taylor RB. Family medicine: current issues and future practice, 1998.

2 Shang X, Huang Y, Li Bi'e, et al. Residents' awareness of family doctor contract services, status of contract with a family doctor, and contract service needs in Zhejiang Province, China: a cross-sectional study. Int J Environ Res Public Health 2019;16:3312.

3 Medical Reform Office of the State Council of China. Notice on the issuance of guidelines on the promotion of contract services for family doctors. Available: http://www.gov.cn/xinwen/2016-06/06/ content_5079984.htm [Accessed 20 Mar 2021].

4 National Health Commission of the People's Republic of China. The National experience romotion conference on deepening medical reform and China health development summit in 2017 released the typical experiences on deepening medical reform. Available: http:// www.nhc.gov.cn/tigs/ygjb/201708/997a76fd89814d1bae1c9b12 29a91097 [Accessed 20 Mar 2021].

5 Zhang X, Zhang X, Fang P. Meta-analysis of the contracting rate of family doctors in China. Chinese J Health Stat 2019;36:255-7.

6 Chen Y, Wang L, Yan C. Status and influencing factors of family doctor service for key population, Gansu. Modern Prevent Med 2018;45:3550-3.

7 Xiao L, Zhang T, Zhang Y. Reasons and countermeasures of residents signing the contract with the family doctor but not making appointments during the implementation of hierarchical medical system. Chinese General Pract 2018;21:3063-8.

$8 \mathrm{Li} \mathrm{Y}$. Improve the quality of family doctor services and enhance people's sense of gain. China Health Human Res 2018:14-15.

9 National Administration of Traditional Chinese Medicine, National Health Commission of the People's Republic of China. Guiding opinions on standardizing the management of contract services for family doctors. Available: http://yzs.satcm.gov.cn/zhengcewenjian/ 2018-10-10/8052.html [Accessed 20 Mar 2021].

10 Grönroos C. A service quality model and its marketing implications. Eur J Mark 1984;18:36-44.

11 Parasuraman A, Zeitham VA, Berry LL. SERVQUAL: a multiple-item scale for measuring consumer perceptions of service quality. $J$ Retailing 1988;64:12.

12 Fracolli LA, Gomes MFP, Nabão FRZ, et al. Primary health care assessment tools: a literature review and metasynthesis. Cien Saude Colet 2014;19:4851-60.

13 Marcinowicz L, Jamiołkowski J, Gugnowski Z, et al. Evaluation of the trust in physician scale (tips) of primary health care patients in northeast Poland: a preliminary study. Fmpcr 2017;1:39-43.

14 Wang C, Yan S, Jiang H, et al. Residents' willingness to maintain contracts with family doctors: a cross-sectional study in China. $J$ Gen Intern Med 2021;36:622-31.

15 Jing L, Shu Z, Sun X, et al. Factors influencing patients' contract choice with general practitioners in Shanghai: a preliminary study. Asia Pac J Public Health 2015;27:77S-85.

16 Abuosi AA, Atinga RA. Service quality in healthcare institutions: establishing the gaps for policy action. Int $J$ Health Care Qual Assur 2013;26:481-92.

17 Ohtsuki T, Inagaki M, Oikawa Y, et al. Multiple barriers against successful care provision for depressed patients in general internal medicine in a Japanese rural hospital: a cross-sectional study. BMC Psychiat 2010;10:30.

18 Riley RD, Ensor J, Snell KIE, et al. Calculating the sample size required for developing a clinical prediction model. BMJ 2020;368:m441.

19 Zhao P, Wang Y, Lin Z. Scale for service quality evaluation of rural family doctors: development, reliability and validity. Chinese General Pract 2021;24:812-7.

20 Aghamolaei T, Zare S. Quality gap of educational services in viewpoints of students in Hormozgan University of medical sciences. BMC Med Educ 2008;8:34.

21 Cronin JJ, Taylor SA. Servperf versus Servqual: reconciling performance-based and Perceptions-Minus-Expectations measurement of service quality. J Mark 1994;58:125-31.

22 Fan L-hua, Gao L, Liu X. Patients' perceptions of service quality in China: An investigation using the SERVQUAL model. PLoS One 2017; 12:e190123.

23 Redondo Martín S, Bolaños Gallardo E, Almaraz Gómez A, et al. [Perceptions and expectations on primary health care: a new form of identifying improvements in the care system]. Aten Primaria 2005;36:358-63.

24 Yang Y, Lee EY, Kim H-S, et al. Effect of a mobile Phone-Based Glucose-Monitoring and feedback system for type 2 diabetes management in multiple primary care clinic settings: cluster randomized controlled trial. JMIR Mhealth Uhealth 2020;8:e16266.

25 Hou C, Carter B, Hewitt J, et al. Do mobile phone applications improve glycemic control $(\mathrm{HbA1c})$ in the self-management of diabetes? A systematic review, meta-analysis, and grade of 14 randomized trials. Diabetes Care 2016;39:2089-95.

26 Kuang L, Liang Y, Mei J, et al. Family practice and the quality of primary care: a study of Chinese patients in Guangdong Province. Fam Pract 2015;32:557-63.

27 Hamilton SJ, Mills B, Birch EM, et al. Smartphones in the secondary prevention of cardiovascular disease: a systematic review. BMC Cardiovasc Disord 2018;18:25.

28 Qiao Y, Chen W, Yang J. Continuity evaluation of contracted family doctor services in rural areas using perceived quality framework. Chinese General Pract 2021;24:2440-4.

29 Goldfield N, Gnani S, Majeed A. Primary care in the United States: profiling performance in primary care in the United States. BMJ 2003;326:744-7.

30 Yu X, Xiao-Hong W, Jia C. Challenges in establishing a graded diagnosis and treatment system in China. Fam Pract 2021.

31 Cunningham PJ. High medical cost burdens, patient trust, and perceived quality of care. J Gen Intern Med 2009;24:415-20.

32 Zhou S, Huang T, Li A, et al. Does universal health insurance coverage reduce unmet healthcare needs in China? Evidence from the National Health Service Survey. Int J Equity Health 2021;20:43.

33 Yin T, Liu Z, Xu Y. Analysis of crisis management of medical disputes in China and Australia: a narrative review article. Iran J Public Health 2019;48:2116-23.

34 Xiao Y, Zhao K, Ma Z-X, et al. Integrated medical rehabilitation delivery in China. Chronic Dis Transl Med 2017;3:75-81. 